\title{
La revolución en suspenso
}

\author{
Revolution on hold
}

Sebastián Tobón

tobon.sebastian@gmail.com

DOI: http://doi.org/10.15366/bp2019.21.021

Bajo Palabra. II Época. No21. Pgs: 383-392 


\section{Resumen}

La reflexión que aquí se presenta pretende mostrar los problemas fundamentales del culto a la espontaneidad que abunda no sólo en el ámbito político sino también en el ámbito académico. Se intenta mostrar de qué manera la política del presente necesita, fundamentalmente, un momento de pausa teórica, no sólo para analizar los propios alcances, sino para descubrir los medios más adecuados a las propias intenciones políticas. Esta reflexión sobre la praxis política da lugar también a reflexiones sobre la filosofía moral en general, específicamente sobre las posibilidades materiales de la acción moral en el contexto social del capitalismo.

Palabras Clave: praxis politica, acción moral, revolución, teoria, Theodor W. Adorno, Slavoj Zizek, Christoph Türcke.

\section{Abstract}

Here we present a reflection that seeks to show the fundamental problems of the cult of spontaneity that is prevalent not only in the political sphere but also in the academic. I attempt to show how the politics of the present fundamentally needs a moment of theoretical pause, not only to analyze its own scope, but also to discover the means most suited to its own political intentions. This reflection on political praxis also gives rise to reflections on moral philosophy in general, specifically on the material possibilities of moral action in the social context of capitalism.

Keywords: political praxis, moral action, revolution, theory, Theodor W. Adorno, Slavoj Zizek, Christoph Türcke. 
A Jairo Escobar, a sus rebuznitos y maullidos

\section{Revolución en suspenso: sobre la negación de la praxis política}

LA SUSPENSIÓN DE LA PRAXIS es, en las condiciones existentes, aún más importante que la praxis misma. Mejor: en lo dado, la suspensión de la praxis resulta, en cierto modo, una instancia menos inmediata, menos inconsciente. Pero hay que diferenciar modos de suspensión de la praxis. Por supuesto muchas teorías liberales —entre ellas, el positivismo científico preponderantemente- son, por principio, contrarias a cualquier praxis transformadora del mundo. Al menos para sí, el positivismo científico conserva una auto justificada distancia del devenir social o político. Y digo auto justificada porque $-\mathrm{y}$ esto es algo que siempre se puede anticipar- incluso este alejamiento, en apariencia consciente respecto del mundo de los valores, es ya por sí mismo una praxis específica. Es un hecho, pues, que cuando aquí se habla de una suspensión de la praxis no se hace referencia a aquella ideología científica que tiene el trabajo cerebral por una materia substraída del mundo de la vida. El correlato social necesario de esa ideología es el practicismo empresarial, y su versión política, el activismo universal. Es frente a este correlato que la suspensión de la praxis adquiere todo su sentido, pues en ella se tiende a la plenitud y a la dotación de sentido de todos aquellos espacios vacíos que abre la pura espontaneidad política.

Pero ¿qué significa en realidad el momento de suspensión? Para Adorno, como lo muestra Christoph Türcke en la traducción que aquí se presenta, esta suspensión se encuentra enmarañada dentro de la paradójica condición de ser impostergable, al mismo tiempo que imposible: "El absurdo en el que se encuentra la praxis hechizada, en realidad, clama por una pausa reflexiva”. Necesidad de la praxis e imposibilidad de una praxis verdaderamente transformadora constituyen la ontología social de nuestro capitalismo tardío. Más allá de ser una observación meramente subjetiva y de cuño conservador, la visión de una praxis imposible se basa en una descripción de la realidad como de un mundo sobre determinado prácticamente. Esta sobre determinación práctica ocupa todas las dimensiones de la vida, pues ella misma es una exhortación insuperable. Configura los espacios prácticos y objetivos de la vida 
y, de la misma manera, la estructura subjetiva. Espacios que exhortan una acción constante, inagotable, injustificadamente insuperable como en el mundo del trabajo, constituyen, al mismo tiempo, un proceso de construcción de subjetividades en las que la ansiedad práctica se erige como el punto de toque de la personalidad. Lo absolutamente otro de dicha saturación práctica de la vida sería la pura contemplación. Contemplación, en un sentido crítico, sería aquello que ya Martin Seel ha resaltado como núcleo práctico de la filosofía adorniana. Reconociendo los problemas encarnados en las teorías morales tradicionales (v.gr. Kant), se puede reconocer en Adorno el impulso antiautoritario de una moral que se basa en la posibilidad de reconstruir la experiencia dañada del sujeto a partir de una relación justa con el entorno. ${ }^{1}$ En el mismo contexto de una crítica al sujeto constitutivo de la filosofía tradicional, una idea de la vida práctica como contemplación implicaría un trato con la objetividad del mundo, de guisa tal que este no se haga preso de los fines subjetivos. La resistencia política, toda actitud moral en general, tendría que actuar bajo el mandato de no fijar "el objeto a las propias intenciones" de la consciencia. ${ }^{2}$ Esta suavidad y ternura respecto de la realidad tendrían su lugar, justamente, en una capacidad históricamente inhibida, a saber, la capacidad de contemplar. En principio, contemplar es, entonces, no actuar. Aquí habría que fijar una diferencia fundamental con el modelo de vida contemplativa (bios theoretikós) de la antigüedad. Mientras que el modelo aristotélico enfatiza el momento teórico de esta suspensión práctica, la filosofía de Adorno enfatizaría, por el contrario, el carácter práctico de esta negación de la praxis (Praxisverweigerung), es decir, el carácter práctico del momento teórico. La suspensión de la praxis es, entonces, una consciencia práctica alcanzada, no meramente un momento de aprehensión política. Es consciencia (o autoconsciencia) no en el sentido de un apartar los deseos o toda fáctica vitalidad; es consciencia en el sentido de una comprensión de los mecanismos de reproducción de las fuerzas sociales inmanentes. Va a decir Adorno en Mínima Moralia: "La pura acción (Tathandlung) es la vileza proyectada en 'el cielo estrellado sobre nosotros'. En cambio, la mirada de largo alcance, contemplativa, ante la que se despliegan los hombres y las cosas, es siempre aquella en la que el impulso hacia el objeto queda detenido y sujeto a reflexión". ${ }^{3}$

"La filosofía habla mucho sobre el hacer (Tun), pero poco acerca de la renuncia (Lassen)" ${ }^{4}$ El pensamiento filosófico, hasta ahora, ha sido un juicio sumario contra

\footnotetext{
${ }^{1}$ Martin Seel, Sich bestimmen lassen, Suhrkamp Verlag, Frankfurt am Main, 2002, p. 30.

2 Ibid. p. 32.

3 Theodor W. Adorno, Minima Moralia, GS.4, p. 94.

${ }^{4}$ Martin Seel, Sich bestimmen lassen, Suhrkamp Verlag, Frankfurt am Main, 2002, p. 279.
} 
toda pasividad, contra toda renuncia a la transformación de la realidad, contra toda abstinencia interventiva. Apartarse y "dejarse determinar" sería un destino históricamente necesario. Pero este alejamiento del pensador no es un alejamiento de la filosofía en cuanto a sus contenidos. En general, este aislamiento no es el mero guarecerse de la consciencia en la interioridad —antípoda de un mundo donde la libertad práctica no está a la mano-. La filosofía que se aleja y se suspende es aquella que sabe que solo puede realizarse inmediatamente a costa de dolores y sufrimientos injustificados.

"La filosofía, que otrora pareció obsoleta, se mantiene con vida porque se dejó pasar el instante de su realización". ${ }^{5}$ La realización sin mediaciones de la filosofía, lo que así fue interpretado por el culto soviético a la espontaneidad, siempre pasa por encima de toda dignidad objetiva. El activismo burgués se filtra en la pretendida praxis anti burguesa. Así lo deja entrever el mismo Lenin cuando en su famoso escrito programático "¿Qué hacer?" apunta hacia la enfermedad fundamental del activismo, incluso de corte marxista: "Quien conozca, por poco que sea, el estado efectivo de nuestro movimiento verá forzosamente que la vasta difusión del marxismo ha ido acompañada de cierto menosprecio del nivel teórico". ${ }^{6} \mathrm{Y}$ es justo este el punto donde se hace evidente la relevancia de una suspensión de la praxis, la profunda y radical importancia del momento contemplativo. No es solo que el hacer sea contraproducente en una sociedad donde todas las estructuras sociales tienden a la reproducción material e inmaterial del espíritu de la época, sino que este espíritu de la época es, esencialmente, anti teórico; se basa, antes que nada, en el impulso inmediato de la acción y en el desdeño y menosprecio de cualquier plan. La falta de plan es, en el caso de la praxis revolucionaria, la falta de toda substancia. La rabia, la alegría, o la simple esperanza en las buenas acciones, nunca terminan de constituirse en motores legítimos de una acción verdaderamente transformadora. La buena voluntad, como valor típicamente liberal, no solo condenó el mundo de la vida de las sociedades liberales a la dinámica infructuosa del girar sobre sí misma, una dinámica de producción-solución-producción de problemas, una tautología sostenida que bien puede, a veces, dar la impresión de movimiento, también condenó, colateralmente, a la izquierda que, en un gesto de lo más irracional, solo encuentra en la violencia del inmediato volcamiento de la consciencia en la realidad un modus operandi salvador. La estabilización del cambio social se ha logrado, pues, más efectivamente en cuanto más esperanzas sociales se proyectan en los pequeños

\footnotetext{
5 Theodor W. Adorno, Dialéctica Negativa, GS. 6, p. 15.

${ }^{6}$ Vladimir Ilich Lenin, ¿Qué hacer? Problemas candentes de nuestro movimiento, Col. claves para el socialismo, Ministerio del poder popular para la comunicación y la información, Caracas, 2010, p. 39.
} 
planes de contingencia, en las estrategias de choque, en los think tanks (la apariencia de reflexión puesta al servicio del poder, al servicio de la plena praxis), en último término, en el modelo de subjetividad emprendedora que ha logrado acaparar todos los espacios de una libertad posible.

Nada de lo dicho puede desconocer el estado de la sociedad al que se enfrenta el pensamiento. No hay retracción por puro gusto; no es un principio universal, como sí lo es el del escepticismo, del estoicismo o el que se manifiesta en el impulso cientificista del positivismo filosófico. La retracción política es ella misma una estratagema materialista que se compromete no solo con la dignidad de las cosas, sino con su sufrimiento. El estado del mundo es uno tal que ha logrado integrar, del modo más efectivo, las energías revolucionarias a favor de la reproducción social. El ejemplo de China es aleccionador: tal y como ocurrió con la moderna sociedad inglesa nacientemente capitalista — que pudo ceder su poder a la aristocracia-, la clase burguesa china fue capaz de comprometer el poder político —al ya pervertido partido comunista - siempre y cuando se le permitiera enriquecerse sin límite alguno. ${ }^{7}$ Estos compromisos políticos disponen, al mismo tiempo, de las energías transformadoras que se entregan fácilmente como garantía de cuotas burocráticas, de medidas políticas parciales, de acuerdos provisionales, de cogobiernos, de frentes nacionales, etc.

La movilidad es inmanente al concepto de sociedad; cambio y devenir no dependen exclusivamente de nuestro deseo subjetivo o de nuestras intenciones partisanas. El cambio está allí, las oquedades se abren —a veces con nuestra ayuda, a veces sin ella-, pero tienen que ser descubiertas, tienen que ser nombradas. Y este es un trabajo, en esencia, teórico:

¿Cómo, entonces, debemos escapar del callejón sin salida de la deshistorización post-política? ¿Qué hacer después del movimiento de Occupy Wall Street, cuando las protestas que comenzaron lejos (Oriente Medio, Grecia, Espańa, Reino Unido) alcanzaron el centro, y ahora se refuerzan y expanden por todo el mundo? Aquello a lo que deberíamos resistirnos en esta etapa es precisamente a una rápida traducción de la energía de la protesta en un conjunto de demandas pragmáticas «concretas». ${ }^{8}$

La creación práctica del vacío, que sucede necesariamente como producto de las experiencias sociales de insatisfacción y sufrimiento, debe, también, descubrir aquello de lo que cada situación está "preñada". El trabajo práctico que abre oquedades en la inmanencia social depende insuperablemente de un momento radicalmente

\footnotetext{
7 Car. Slavoj Zizek, Less Than Nothing. Hegel and the Shadow of Dialectical Materialism. Ed. Verso, New York, 2012, p. 720 y ss.

${ }^{8}$ Slavoj Zizek, Ibid.p. 720. La traducción castellana se basa en la versión de Antonio José Antón Fernández.
} 
cerebral. La respuesta a la pregunta que se abre con cada momento de protesta no se responde en la arena misma:

¿Qué forma de organización social puede reemplazar al capitalismo realmente existente? ¿Qué tipo de nuevos líderes necesitamos? ¿Y qué órganos, incluyendo aquellos de control y represión? Las alternativas del siglo XX obviamente no funcionaron. Aunque es emocionante disfrutar de los placeres de la "organización horizontal», de muchedumbres protestatarias con su solidaridad igualitaria y sus debates abiertos, tales debates tendrán que materializarse no solo alrededor de unos nuevos Significantes-Amo $[\ldots]^{9}$

En efecto, tales debates han de materializarse en el esfuerzo consciente de dar una respuesta teórica a las preguntas prácticas, por muy urgentes que estas parezcan. Probablemente, nada era más urgente para Lenin en 1907 que continuar con el camino revolucionario. Pero, en medio de las premuras y los errores tácticos de la izquierda soviética —el apoyo a los poderes tradicionales y a la vieja burguesía, así como su beneplácito en el fiasco táctico de la Primera Guerra Mundial-, acertó Lenin con la decisión de exiliarse en varios países de Europa. Su estancia final en Zúrich sirvió, entre muchas otras cosas, a la posibilidad de entregarse a la lectura de la Ciencia de la lógica de Hegel. El "caso Lenin" ilustra con claridad el momento "adorniano" de la posición de Zizek. ${ }^{10}$ Esta suspensión filosófica profundizó, en una medida que hoy es difícil calcular, la postura revolucionaria de Lenin. Sin tomar de manera mistificadora su regreso absolutamente práctico como una revelación necesaria de la suspensión filosófica, hay en toda esta constelación histórica una capacidad ilustrativa que pocos argumentos podrían ostentar.

La traducción que aquí se presenta fue terminada cuando Jairo Escobar aún vivía. De hecho, fue revisada por él, casi anticipando su propio homenaje. Él consideró este texto de Christoph Türcke como herramienta fundamental y significativa en nuestro presente. Lo sigue siendo aún por razones de contingencia política, a pesar de que es un texto que intentaba comprender la realidad de comienzos de los años noventa. Es por todo ello que aquí no solo se trata de un homenaje dirigido a

\footnotetext{
9 Slavoj Zizek, Ibid., p. 721. La traducción castellana se basa en la versión de Antonio José Antón Fernández.

10 "A pesar de su redescubrimiento de Hegel [...] [e]n sus cuadernos de notas, Lenin aún lucha con el mismo problema de Adorno en su "dialéctica negativa": cómo combinar el legado de Hegel de la crítica de toda inmediatez, de la mediación subjetiva de toda objetividad dada, con el mínimum de materialismo que Adorno llama "preeminencia de lo objetivo". Slavoj Zizek, Revolution at the gates, Ed. Verso, New York, 2004, p. 179.
} 
una persona que encarnó sin tacha aquel esfuerzo no resignado por dotar al pensamiento crítico y a la praxis política de contenido; se trata también de la prohibición y la lucha contra las drogas en relación con el pseudoactivismo liberal -asunto con el que inicia el texto en cuestión y que lo acompańa como motivo permanente-, cuestiones que son parte de la agenda del presente, tanto en el contexto colombiano como en la constelación geopolítica que se ha establecido luego de la elección de Trump en los Estados Unidos. ${ }^{11}$ En ese sentido, esta traducción es un material sensible, venido del pasado para ayudarnos a reflexionar sobre problemas que no dejan de repetirse una y otra vez, como por efecto de una maldición milenaria.

${ }^{11}$ Hace apenas unos días se firmó en Colombia el decreto presidencial que penaliza nuevamente la dosis mínima de drogas, tras algunos años de avances en el sentido de una solución original al problema, a través de la despenalización paulatina del porte. 


\section{REFERENCIAS BibLIOGRÁficas}

\section{Bibliografía principal}

Adorno, Th. W. Gesammelte Schrifften. Herausgegeben von Roll Tiedemann unter Mitwirkung von Gretel Adorno, Susan Buck-Morss und Klauss Schutz. Frankfurt am Main: Suhrkamp Verlag \& Digitale Bibliotek, 2004.

- Obra Completa. Compilado por RolfTiedemann, con la colaboración de Gretel Adorno, Susan Buck-Morss y Klauss Schutz. Madrid: Akal, 2014.

\section{Bibliografía secundaria:}

Vladimir Ilich Lenin, ¿Qué hacer? Problemas candentes de nuestro movimiento, Col. claves para el socialismo, Ministerio del poder popular para la comunicación y la información, Caracas, 2010.

Martin Seel, Sich bestimmen lassen, Suhrkamp Verlag, Frankfurt am Main, 2002.

Slavoj Zizer, Less Than Nothing. Hegel and the Shadow of Dialectical Materialism. Ed. Verso, New York, 2012.

- Revolution at the gates, Ed. Verso, New York, 2004.

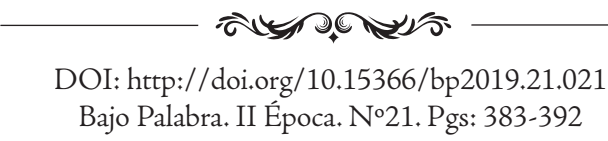


